\title{
Hydrogen Partitioning as a Function of Time-on-Stream for an Unpromoted Iron-Based Fischer-Tropsch Synthesis Catalyst Applied to CO Hydrogenation
}

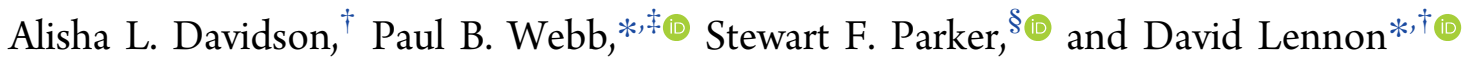 \\ ${ }^{\dagger}$ School of Chemistry, University of Glasgow, Joseph Black Building, Glasgow G12 8QQ U.K. \\ ${ }^{\ddagger}$ School of Chemistry, University of St Andrews, St Andrews KY16 9ST, U.K. \\ ${ }^{\S}$ ISIS Facility, STFC Rutherford Appleton Laboratory, Chilton, Didcot, Oxon OX11 0QX, U.K. \\ Supporting Information
}

\begin{abstract}
Inelastic neutron scattering (INS) is employed to examine the evolution of a promoter-free iron-based Fischer-Tropsch synthesis catalyst ( $\sim 10$ g catalyst charge) that is exposed to ambient pressure CO hydrogenation at $623 \mathrm{~K}$ for up to 10 days time-on-stream (T-o-S). The longer reaction time is selected to better understand how the formation of a previously described hydrocarbonaceous overlayer corresponds to the catalyst conditioning process. Although the onset of pseudo steady-state reactor performance is observed at approximately $9 \mathrm{~h}$ T-o-S, INS establishes that the intensity of the $\mathrm{C}-\mathrm{H}$ stretching mode of the $\mathrm{sp}^{3}$-hybridized component of the hydrocarbonaceous overlayer saturates at about $24 \mathrm{~h} \mathrm{~T}$-o-S, while the corresponding intensity of the $\mathrm{C}-\mathrm{H}$ stretching mode of the $\mathrm{sp}^{2}$-hybridized component requires $100-200$ $\mathrm{h}$ T-o-S to achieve saturation. This novel series of measurements reveal different aspects of the complex catalyst evolutionary process to be indirectly connected with catalytic turnover.
\end{abstract}

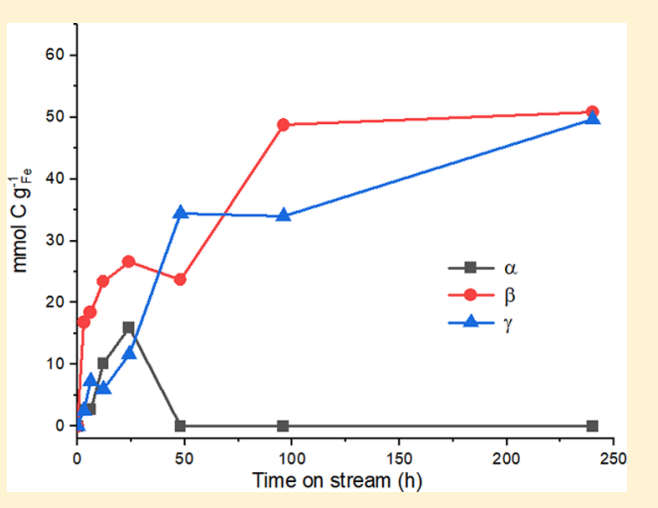

\section{INTRODUCTION}

Fischer-Tropsch synthesis (FTS) involves the catalytic conversion of synthesis gas, a mixture of $\mathrm{CO}$ and $\mathrm{H}_{2}$, to produce a wide range of hydrocarbon products, with the synthesis gas being obtained from biomass, natural gas, or coal. ${ }^{1-3}$ The hydrocarbon product output is dependent on not only the reaction conditions employed but also the catalyst used. ${ }^{4}$ Current commercial processes operate with iron- and cobalt-based catalysts. ${ }^{3}$ Iron FTS catalysts convey some favorability over cobalt catalysts on grounds of low cost and tolerance to poisons. Furthermore, through the addition of promoters or changes to reaction conditions, they are responsive to manipulation of the product slate to produce olefins and oxygenates. 3,5

Iron-based FTS catalysts are known to go through an "evolutionary" period in the early stages of reaction. In a pretreatment step, or under FTS conditions, the oxidic precatalyst is reduced toward $\alpha$-Fe and/or iron carbides. ${ }^{3,5-7}$ The final catalyst composition and the extent of the evolutionary phase is dependent on the reaction conditions utilized. ${ }^{3-5}$ The active phase of iron FTS catalysts is still under debate, but several studies have independently demonstrated a clear correlation between FT activity and the formation of iron carbides, ${ }^{8-11}$ in particular, the Hägg carbide. Concerning the duration of this initial catalyst conditioning period, PérezAlonso et al. report that catalytic activity required a period of ca. $120 \mathrm{~h}$ to reach the steady state, with the changes attributed to variations in the composition of the iron catalyst in the initial stages of the reaction. ${ }^{12}$ The duration of these changes is in general agreement with Buker and co-workers, who report an iron FTS catalyst to require approximately $100 \mathrm{~h}$ time-onstream (T-o-S) to attain steady-state operation. ${ }^{13}$ However, it is noted that the extent of the initial conditioning period will be dependent on several factors including reactor configuration, GHSV, gas consumption, pressure, and temperature. It is the iron-based FTS catalyst evolutionary phase that is the principal matter of interest in this communication.

The present study builds upon previous inelastic neutron scattering (INS) investigations of Fe-based FTS catalysts that correlate ambient pressure $\mathrm{CO}$ hydrogenation activity with the formation of a hydrocarbonaceous overlayer. ${ }^{14-19}$ In particular, a recent communication by Warringham et al. examined the evolution of the hydrocarbonaceous overlayer over a reaction period of $24 \mathrm{~h} \mathrm{~T}$-o-S that revealed the overlayer to be dominated by polyaromatic moieties alongside a less prominent aliphatic component. ${ }^{18}$ With reference to sections of the selective hydrogenation literature, ${ }^{20}$ it is further suggested that the overlayer defines the active sites on the iron carbide surface. ${ }^{18}$ After $24 \mathrm{~h}$ T-o-S, the olefinic/aromatic

Received: August 21, 2019

Revised: October 23, 2019

Accepted: December 9, 2019

Published: December 9, 2019 
moiety of the overlayer continues to increase, while the population of the aliphatic feature appears to saturate after approximately $6 \mathrm{~h}^{18}$ If the hydrocarbonaceous overlayer does indeed play an active role in determining catalytic performance, it is opportune to consider how the nature of the overlayer is modified for reaction times beyond $24 \mathrm{~h}$ and to concentrate on the $\sim 100 \mathrm{~h}$ T-o-S duration, as highlighted by Pérez-Alonso and co-workers and Buker and co-workers. ${ }^{12,13}$

It is noted that the use of ambient pressure $\mathrm{CO}$ hydrogenation as a test reaction is selected for its compatibility with the INS technique. ${ }^{15-18}$ Interestingly, the INS spectrum for the hydrocarbonaceous overlayer that forms for extended periods of T-o-S for the iron-based FTS reference catalyst examined here ( $\mathrm{CO}$ hydrogenation, ambient pressure, $623 \mathrm{~K}$, $24 \mathrm{~h} \mathrm{T-o-S}$ ) is remarkably similar to that of a technical catalyst that has been extracted from a large-scale commercial FTS unit operation. ${ }^{18}$ This outcome signifies that the hydrocarbonaceous overlayer is indeed relevant to the large-scale Fe-based FT catalyst and FT process.

Given the industrial significance of iron-based FTS catalysis, ${ }^{3}$ this article seeks to build on the work of Warringham et al. ${ }^{18}$ and to apply the INS technique in order to discover, for ambient pressure $\mathrm{CO}$ hydrogenation at $623 \mathrm{~K}$, how hydrogen is partitioned within an unpromoted iron FTS catalyst for extended periods of T-o-S $(0-240 \mathrm{~h})$. Postreaction ex situ characterization includes elemental analysis, $\mathrm{X}$ ray diffraction (XRD), Raman spectroscopy, and temperatureprogrammed oxidation (TPO) measurements. This combination of techniques determines how the form and nature of the overlayer is modified during the transition from a hematite precatalyst to a catalyst stabilized for $\mathrm{CO}$ hydrogenation activity. Collectively, this novel series of measurements over this extended reaction time reveal different aspects of the complex catalyst evolutionary process to be indirectly connected with catalytic turnover.

\section{EXPERIMENTAL SECTION}

2.1. Catalyst Preparation. The iron oxide sample, with no promoters or modifiers, utilized for this experiment was prepared using a co-precipitation of iron nitrate (SigmaAldrich, 99.99\%) and sodium carbonate (Sigma-Aldrich, 99.99\%), using a Mettler Toledo LabMax batch reactor apparatus to ensure reproducibility of catalyst synthesis. ${ }^{18}$ The resulting slurry was filtered, washed with deionized water, and calcined using the same stepwise programme described elsewhere. ${ }^{18}$ Samples were ground and sieved to a particle size range of $250-500 \mu \mathrm{m}$. In a separate experiment (not presented here), this material was examined for FTS activity on a semitechnical test facility operating with a syngas pressure of 25 Barg and a temperature range of $300-350^{\circ} \mathrm{C}$ : The catalyst displayed sustained FTS activity for a test period duration of 6 days. It is noted that although this catalyst was prepared in exactly the same way as the catalyst examined for $0-24 \mathrm{~h}$ by Warringham and co-workers, ${ }^{18}$ it is a different batch of catalyst.

2.2. INS Measurements. For INS measurements, approximately $10 \mathrm{~g}$ of the catalyst was loaded into an Inconel reactor cell and attached to a custom-built sample preparation apparatus. ${ }^{21}$ As the present study concentrates on using INS to characterize the form of the hydrocarbonaceous overlayer over an extended $240 \mathrm{~h}$ period of reaction, only the relatively larger scale INS reactor is employed in this work. Previously, the authors have considered differences in the gas/solid exchange dynamics that can lead to retardation of reaction processes in the INS reactor compared to a more conventional microreactor arrangement. ${ }^{15,17}$ Crucially, for this study, as all reactions are undertaken using the INS reactor, post-reaction temporal profiles using ancillary analytical methods can be directly compared to the INS spectra.

For CO hydrogenation measurements, the iron oxide catalyst samples were heated to $623 \mathrm{~K}$ at $5 \mathrm{~K} \mathrm{~min}^{-1}$ under a flow of carbon monoxide $\left(75 \mathrm{~mL} \mathrm{~min}^{-1}\right.$, CK Gas, 99.9\%) and hydrogen $\left(150 \mathrm{~mL} \mathrm{m^{-1 }}\right.$, CK Gas, $\left.99.9 \%\right)$ in a carrier gas (He, $600 \mathrm{~mL} \mathrm{~min}^{-1}$, CK Gas, 99.9\%, total WHSV of $1.27 \mathrm{~h}^{-1}$ ) and held at this temperature for a predetermined length of time. It is noted that the INS measurements were not consecutive, and each time period analyzed has utilized a different charge of the catalyst. Thus, an approximately $10 \mathrm{~g}$ charge of the catalyst was reacted for $48 \mathrm{~h}$, the reaction quenched, and the catalyst transferred to the INS spectrometer for spectral acquisition. In the case of the $96 \mathrm{~h}$ run, a fresh $10 \mathrm{~g}$ charge of the catalyst was reacted for $96 \mathrm{~h}$ before stopping the reaction and transferring the catalyst to the spectrometer. Likewise for the $240 \mathrm{~h}$ run.

The gas products were analyzed by an in-line mass spectrometer (Hiden Analytical, HPR20 QMS Sampling System). Once the reaction was complete $(t=x \mathrm{~h})$, the reactant gases were stopped, and the sample was left to cool to room temperature in a flow of carrier gas. The reactor cell was isolated and transferred to an argon-filled glovebox (MBraun UniLab MB-20-G, $\left[\mathrm{H}_{2} \mathrm{O}\right]<1 \mathrm{ppm},\left[\mathrm{O}_{2}\right]<2 \mathrm{ppm}$ ) before being loaded into an aluminum INS cell and sealed via an indium wire gasket for INS analysis. ${ }^{22}$ All INS measurements were performed using the MAPS direct geometry spectrometer. ${ }^{23}$ Spectra were recorded at $20 \mathrm{~K}$ at incident energies of 600 and $250 \mathrm{meV}$ using the A chopper package. $^{23}$ Quantification of the $\nu(\mathrm{C}-\mathrm{H})$ modes was achieved following a calibration protocol described elsewhere. ${ }^{18,24}$ For ex situ characterization, reacted samples were subjected to a passivation procedure involving the introduction of small amounts of $\mathrm{O}_{2}$ to the reactor, gradually increasing to atmospheric levels (i.e., $20 \% \mathrm{O}_{2}$ in the gas feed). ${ }^{25}$ The samples prepared in the large-scale INS reactor are referred to as LR- $x$, where $x$ indicates the T-o-S in hours. Three reaction times are considered: 48,96 , and $240 \mathrm{~h}$ T-o-S.

2.3. Post-Reaction Analysis. TPO studies of the largescale samples were carried out ex situ on a microreactor catalyst test line. The apparatus is composed of $1 / 8^{\prime \prime}$ diameter stainless steel Swagelok tubing; a full description of which can be found elsewhere. ${ }^{17,18}$ Approximately, $10 \mathrm{mg}$ of the catalyst was loaded into a $1 / 4^{\prime \prime}$ quartz tube reactor with the reactor plugged with quartz wool. The reactor is housed within a tube furnace (Carbolite MTF 10/15/30) equipped with PID control and a thermocouple that is positioned within the catalyst bed to ensure accurate temperature reading during measurements. Oxygen (5\% in $\mathrm{He}, 70 \mathrm{sccm}, \mathrm{BOC} \mathrm{Ltd}, 99.5 \%$ ) was introduced to the sample, and the reactor was heated to $1173 \mathrm{~K}$ at $5 \mathrm{~K} \mathrm{~min}^{-1}$ using the mass spectrometer to monitor the eluting gases. Quantification of the $\mathrm{CO}_{2}$ peak area was achieved by measuring the $\mathrm{CO}_{2}$ response from the in situ TPO of known masses of graphite (Sigma-Aldrich, 99.9\%). ${ }^{26}$ Previous ex situ TPO measurements have used larger catalyst loadings $(\sim 40 \mathrm{mg})$, but ${ }^{15-19}$ for the extended reaction times under consideration here that resulted in significant carbon retention; such masses caused exhaustion of the oxygen cofeed, compromising carbon quantification. TPO measurements of a lower catalyst mass of $\sim 10 \mathrm{mg}$ ensured that the carbon 
oxidation process remained within quantitative limits for all samples examined.

Ex situ powder XRD was performed using a Panalytical X'Pert PRO MPD equipped with a Co $\mathrm{K} \alpha$ radiation. Ex situ Raman scattering was performed using a Horiba Jobin Yvon LabRam HR confocal Raman microscope and a $532 \mathrm{~nm}$ laser source at $<20 \mathrm{~mW}$ power. Measurements were performed for approximately $5 \mathrm{~min}$. Elemental analysis was performed on an Exeter CE-440 Elemental Analyzer ( detection limit $0.1 \mathrm{wt}$ $\%)$.

\section{RESULTS AND DISCUSSION}

3.1. Reaction Testing Prior to INS Measurements. The catalyst under consideration here is the same as that used in the $24 \mathrm{~h}$ INS study undertaken by Warringham and coworkers, with XRD confirming the phase of the iron oxide sample to be hematite $\left(\alpha-\mathrm{Fe}_{2} \mathrm{O}_{3}\right)$. The sample has been additionally characterized by $\mathrm{N}_{2}$ physisorption, XRD, Raman, scanning electron microscopy, transmission electron microscopy, and inductively coupled plasma-optical emission spectrometry that are described elsewhere. ${ }^{17} \mathrm{CO}$ hydrogenation at ambient pressure and elevated temperature provides information on the surface chemistry of the iron oxide $/ \mathrm{CO} / \mathrm{H}_{2}$ reaction system without the formation of long chain hydrocarbons, which would otherwise interfere and significantly complicate the INS spectra. ${ }^{14-19}$ Figure 1 displays

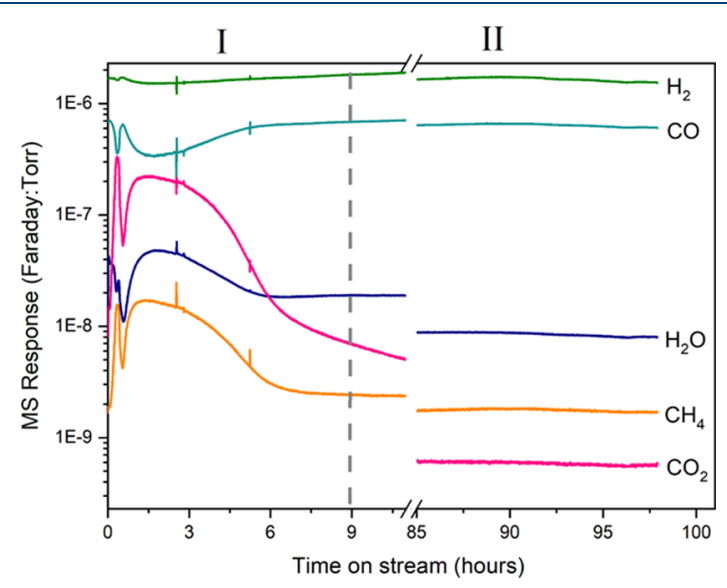

Figure 1. Reaction profile for the sample exposed to $\mathrm{CO}$ hydrogenation conditions at $623 \mathrm{~K}$ for $96 \mathrm{~h}$. Roman numerals indicate different stages within the reaction profile (see the text). The vertical dashed line signifies $9 \mathrm{~h}$ T-o-S.

a representative mass spectrometric profile for a $0-96 \mathrm{~h}$ reaction and, as reported for the $24 \mathrm{~h}$ reaction sequence, it is divisible into two subsections: ${ }^{18}$ (I) the simultaneous production of $\mathrm{H}_{2} \mathrm{O}, \mathrm{CH}_{4}$, and $\mathrm{CO}_{2}$ as the reaction reaches the temperature, followed by (II) the reaction approaching steady-state operation. The latter phase is deemed to be achieved within approximately $9 \mathrm{~h} \mathrm{~T}$-o-S; thereafter, the product distribution is stable. Under these conditions, $\mathrm{CO}$ conversion approximates to $<1 \%$, with catalytic activity approximating to an iron time yield of $6.39 \times 10^{-6} \mathrm{mmol}$ (CO) $\mathrm{g}_{\mathrm{Fe}}^{-1} \mathrm{~s}^{-1}$, similar to values reported in the literature for bulk iron catalysts operating under similar conditions. ${ }^{27}$ It is noted that $\mathrm{CO}_{2}$ production drops quite dramatically over the reaction period. This was also noted by Warringham et al., who suggested the main route of $\mathrm{CO}_{2}$ production to be predominant reduction of $\alpha-\mathrm{Fe}_{2} \mathrm{O}_{3} \rightarrow \mathrm{Fe}^{0}{ }^{18}$ With reference to Figure 1, the decrease in $\mathrm{CO}_{2}$ correlates with the $\mathrm{CO}$ returning to a steady-state regime, suggesting that by approximately $9 \mathrm{~h}$ on stream, the catalyst is fully reduced. Figure 1 highlights the initial conditioning period and the steady-state operation at extended reaction times (0-10 and 85-100 h, respectively). Figure $\mathrm{S} 1$ presents an extended reaction profile that covers the range $0-100 \mathrm{~h}$ T-o-S.

3.2. Post-Reaction Characterization. Elemental analysis of the catalyst before and after exposure to $\mathrm{CO}$ hydrogenation conditions for 48, 96, and $240 \mathrm{~h}$ T-o-S enable the degree of carbon and hydrogen retention within the catalyst to be determined; the results are presented in Table 1. Minimal C

Table 1. Elemental Analysis of the Catalyst before and after Exposure to CO Hydrogenation Conditions for 48, 96, and 240 h T-o-S ${ }^{a}$

$\begin{array}{lcc}\text { sample } & \text { wt \% carbon } & \text { wt \% hydrogen } \\ \alpha-\mathrm{Fe}_{2} \mathrm{O}_{3} & 0.11( \pm 0.08) & 0.08( \pm 0.01) \\ \mathrm{LR}-48 & 23.42( \pm 0.21) & 0.17( \pm 0.05) \\ \mathrm{LR}-96 & 32.83( \pm 0.86) & 0.39( \pm 0.14) \\ \text { LR-240 } & 34.89( \pm 0.66) & 0.27( \pm 0.06)\end{array}$

${ }^{a}$ The standard deviation from measurements performed in duplicate is shown in brackets.

and $\mathrm{H}$ are detected in the unreacted sample. On reaction, there is a systematic trend of increasing $\mathrm{C}$ retention for increasing periods of $\mathrm{T}-\mathrm{o}-\mathrm{S}$, with the $\mathrm{C}$ retention rate decreasing for times $\geq 100 \mathrm{~h}$. Table 1 additionally shows hydrogen retention to be evident but to a much lesser degree than observed for $\mathrm{C}$ and also in a less systematic fashion. Collectively, Table 1 indicates increased retention of $\mathrm{C}$ (major) and $\mathrm{H}$ (minor) up to approximately $100 \mathrm{~h} \mathrm{~T}$-o-S. Indeed, the degree of hydrogen retention is just above the detection levels of the elemental analyzer $(\sim 0.1$ wt $\%)$.

Figure 2 presents the ex situ diffractograms of the catalyst pre- and post-reaction. Samples LR-48, LR-96, and LR-240 h are displayed in Figure $2 \mathrm{~b}$. In contrast to Figure $2 \mathrm{a}$, which distinctly shows hematite $\left(\alpha-\mathrm{Fe}_{2} \mathrm{O}_{3}\right)$ reflections, Figure $2 \mathrm{~b}$ reveals the loss of these features on reduction over the $240 \mathrm{~h}$ period and the emergence of various reflections in the range of $40-60^{\circ}$, signifying the formation of iron carbides. Rietveld refinement of the catalyst samples, details of which are presented within the Supporting Information section (Figures S2 and S3), establishes the presence of a pure Hägg carbide $\left(\mathrm{Fe}_{5} \mathrm{C}_{2}\right)$ phase for the post-reaction samples. Previous work has indicated cementite $\left(\mathrm{Fe}_{3} \mathrm{C}\right)$ to be present in the early stages of the reaction, ${ }^{15}$ but Figure 2 is interpreted as indicating the formation of the Hägg carbide, the proposed active phase, to be completed by $48 \mathrm{~h}$ on stream. The broad reflections at ca. $30^{\circ}$ are attributed to amorphous carbon; the intensity of this feature increases as T-o-S extends from 48 to $240 \mathrm{~h}$.

Figure 3 presents ex situ Raman spectra of the catalyst prior to reaction (Figure $3 \mathrm{a}$ ) and after $240 \mathrm{~h}$ reaction (Figure $3 \mathrm{~b}$ ). The post-reaction sample is indicative of the retention of carbonaceous species, as signified by the " $D$ " and "G" bands that are associated with disordered and ordered graphitic carbon, respectively. ${ }^{28-30}$ Figure $4 \mathrm{~b}$ includes a fit to the G, D1, D3, and D4 states of carbon; consistent with the build-up of an amorphous carbon component.

Figure 4 presents the post-reaction TPO profiles. Previous measurements have identified the presence of three carbonaceous species from TPO measurements on iron-based FTS 


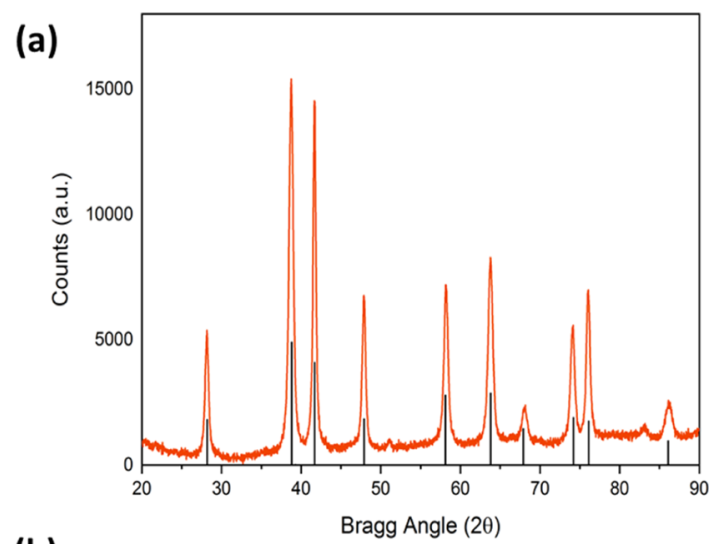

(b)

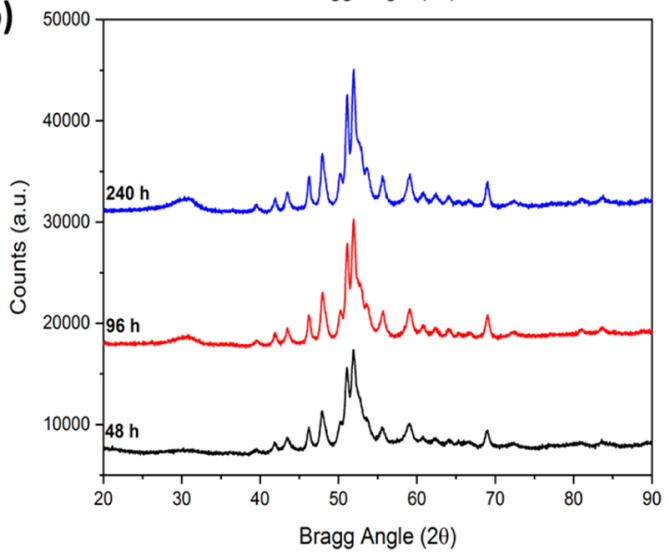

Figure 2. XRD diffractograms of (a) the hematite precatalyst and (b) the catalyst sample after exposure to $\mathrm{CO}$ hydrogenation conditions for 48 (black), 96 (red), and $240 \mathrm{~h}$ (blue) T-o-S. The black sticks in (a) are indicative of reflections corresponding to the $\alpha-\mathrm{Fe}_{2} \mathrm{O}_{3}$ reference diffractogram from the Highscore Plus software package.

catalysts and are assigned as follows: $\alpha$-reactive carbon, $\beta$ amorphous carbon, and $\gamma$-bulk iron carbides. ${ }^{17,18}$ From the profiles observed within this investigation using the large-scale reactor (Figure 4), only the $\beta$ and $\gamma$ features with respective peak maxima of ca. 630 and $680 \mathrm{~K}$ are observed for reaction times of 48, 96, and $240 \mathrm{~h}$. The absence of the $\alpha$ peak (assigned as a precursor for the formation of the hydrocarbonaceous overlayer $)^{19}$ at these reaction times is considered further in Section 3.3. Quantification of the features in the TPO profiles of Figure 4 are tabulated in Table 2 and displayed in Figure 5.

Table 2 shows both the $\beta$ and $\gamma$ features to increase quite steeply up to ca. $100 \mathrm{~h}$ TOS; thereafter, the retention rate is retarded up to $240 \mathrm{~h}$. Alongside the integrated TPO intensities for the 48, 96, and $240 \mathrm{~h}$ data sets, Figure 5 also includes intensity information taken from the earlier $0-24 \mathrm{~h}$ data set for CO hydrogenation over the same promoter-free catalyst under examination here. ${ }^{18}$ It is noted that from 48 to $240 \mathrm{~h}$, a different batch of catalyst was used. In this way, Figure 5 presents a more comprehensive perspective on the dependency of the $\alpha, \beta$, and $\gamma$ TPO features to reaction time using the large-scale INS reactor. The data set is normalized per gram of $\mathrm{Fe}$ in each case. Figure 5 shows that the amorphous carbon component $(\beta)$ displays continued growth up to $96 \mathrm{~h}$ on stream, after which it saturates. The iron carbide component $(\gamma)$ on the other hand exhibits an intense growth period up to $48 \mathrm{~h}$ on stream but, thereafter, shows a reduced rate of growth up to $240 \mathrm{~h}$ TOS. Overall, as a function of TOS utilizing the
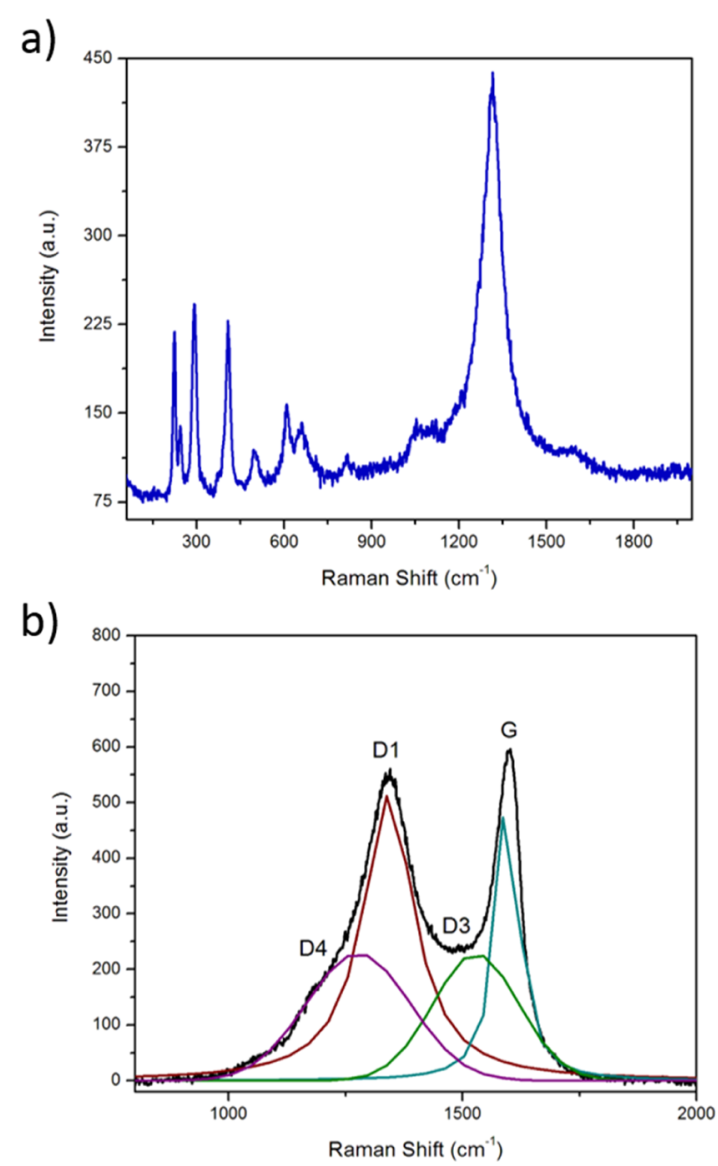

Figure 3. Raman spectra for the promoter-free iron oxide catalyst: (a) as-prepared and (b) LR-240 (exposure to CO hydrogenation conditions for $240 \mathrm{~h}$ ). The colored lines (brown, green, purple, and turquoise), respectively, represent spectral deconvolution of carbonaceous D1, D3, D4, and G features (see the text).

large-scale reactor, Figure 5 shows the following: (i) the $\alpha$ feature grows and then declines within the first $50 \mathrm{~h}$, and (ii) the $\beta$ and $\gamma$ features progressively increase up to a region of 100-200 h, where their populations appear to saturate. The apparent "dip" at $50 \mathrm{~h}$ in the $\beta$ profile of Figure 5 is thought to reflect some variance in the testing and/or post-reaction measurement of different batches of the hematite precatalyst.

Comparing the TPO profiles of Figure 5 with the XRD data of Figure 2 indicates that the previously adopted TPO assignments may be over-simplistic. Specifically, XRD unequivocally shows saturation of the iron carbide structure by $48 \mathrm{~h} \mathrm{~T}$-o-S, yet the intensity of the $\gamma$ feature in the TPO plots progressively increases significantly beyond that reaction time. Adding further uncertainty on the validity of the original assignments is the observation that the intensity profile of the TPO $\alpha$ species of Figure 5 more correctly correlates with the carbide feature detected by XRD (Figure 2). The matter of previously unrealized hidden complexity within the TPO spectrum will be revisited in the Discussion section (Section 4).

3.3. Inelastic Neutron Scattering. Figure 6 presents the INS spectra of the reacted samples and the sample that was dried and not exposed to reaction conditions (black), recorded at incident energies of 650 and $250 \mathrm{meV}$. The spectra for 3 and $6 \mathrm{~h}$ have previously been reported and are included here to convey the full hydrocarbonaceous overlayer evolution. ${ }^{18}$ At 
(a)

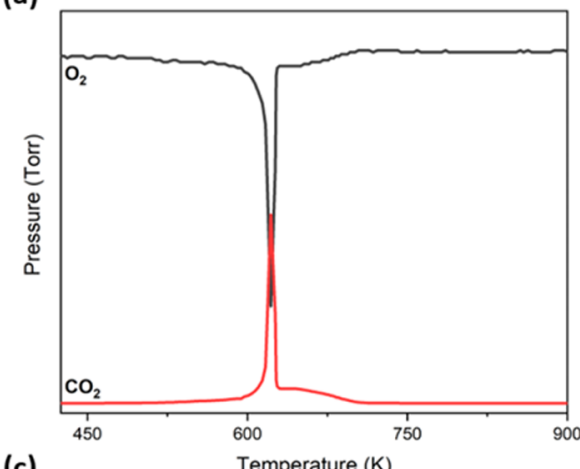

(c)

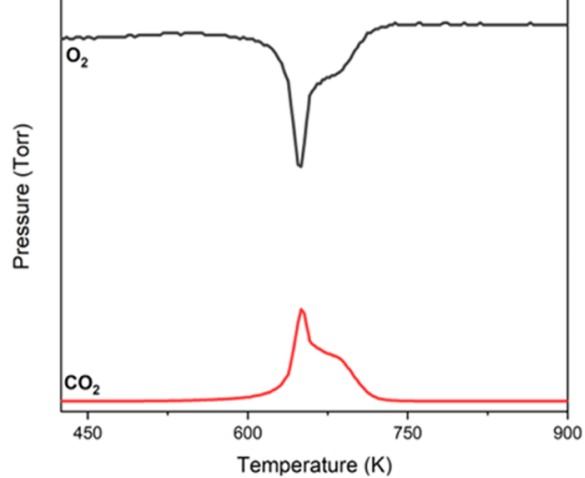

(b)

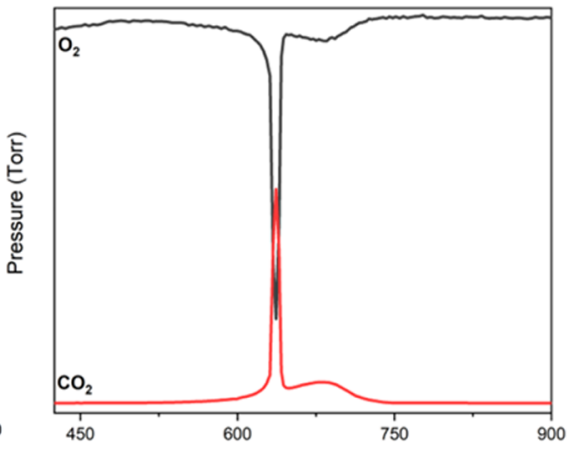

(d)

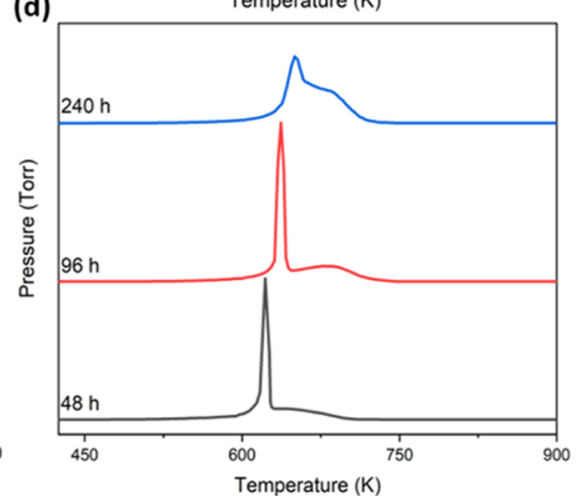

Figure 4. Ex situ TPO MS profiles with oxygen-associated consumption for samples exposed to CO hydrogenation conditions at $623 \mathrm{~K}$ for (a) 48 h, (b) 96 h, and (c) 240 h. (d) Stacked ex situ TPO MS profiles for 48 (black), 96 (red), and 240 h (blue) reactions.

Table 2. Quantified Peak Areas and Peak Maximum Temperatures from the TPO Studies Involving Samples from the Large-Scale INS Reactor

\begin{tabular}{lccccc} 
& \multicolumn{2}{c}{$\beta$ peak } & & \multicolumn{2}{c}{$\gamma$ peak } \\
\cline { 2 - 3 } \cline { 5 - 6 } sample & $\mathrm{C}$ content $^{b}$ & $T_{\max }{ }^{c}$ & & $\mathrm{C}$ content $^{b}$ & $T_{\max }{ }^{c}$ \\
LR $^{a}-48$ & 23.67 & 622 & & 34.46 & 652 \\
LR-96 & 48.74 & 636 & & 34.00 & 682 \\
LR-240 & 50.86 & 652 & & 49.61 & 685
\end{tabular}

${ }^{a}$ LR-large-scale reactor. ${ }^{b} \mathrm{C}$ content in mmol C $\mathrm{g}_{\mathrm{Fe}}{ }^{-1} \cdot{ }^{c} T_{\max }$ in $\mathrm{K}$.

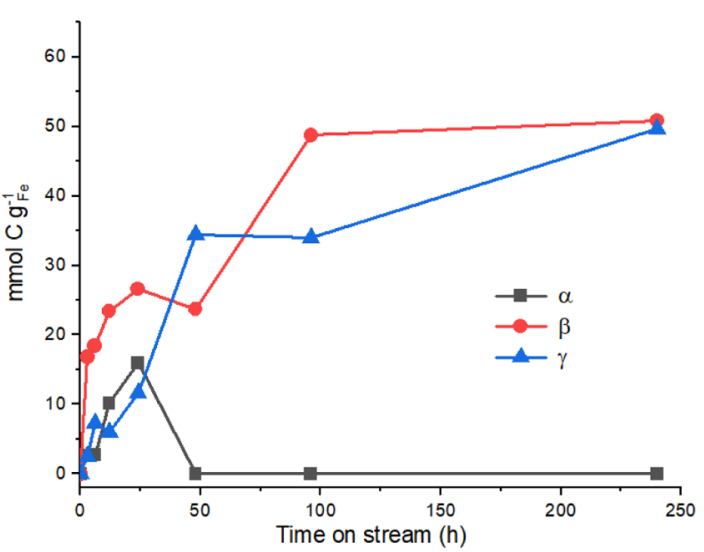

Figure 5. Carbon content of the three TPO species $(\alpha, \beta, \gamma)$ identified from TPO measurements, Figure 4 (see the text for assignments).

$650 \mathrm{meV}$, Figure $6 \mathrm{a}$ shows that the spectra are defined by the presence of a $\nu(\mathrm{C}-\mathrm{H})$ feature consisting of a main peak at $3048 \mathrm{~cm}^{-1}$ with a noticeable shoulder at ca. $2932 \mathrm{~cm}^{-1}$. These bands are respectively assigned to the $\nu(\mathrm{C}-\mathrm{H})$ modes of $\mathrm{sp}^{2}$ and $\mathrm{sp}^{3}$-hybridized carbons. ${ }^{16,17}$ In contrast, the unreacted sample $(0 \mathrm{~h})$ is practically featureless, except for a small but noticeable peak at $3633 \mathrm{~cm}^{-1}$ that is attributed to the $\nu(\mathrm{O}-\mathrm{H})$ mode of terminal hydroxyl groups. With T-o-S, the intensity of the $\nu(\mathrm{C}-\mathrm{H})$ features increase, while the $\nu(\mathrm{O}-\mathrm{H})$ mode is not present from $3 \mathrm{~h}$ onward, indicating a progressive deposition of the hydrocarbonaceous material and the removal of the small population of surface hydroxyls.

At $250 \mathrm{meV}$ (Figure 6b), the clean, dehydrated sample has a significant peak at $797 \mathrm{~cm}^{-1}$. Following previous studies, this can be attributed to a spinon mode of the hematite precatalyst. ${ }^{17}$ The feature is no longer present at $3 \mathrm{~h}$ reaction time, signifying the loss of the hematite structure as the carburization process advances with extended T-o-S. The $3 \mathrm{~h}$ spectrum is characterized by the emergence of two weak features at 591 and $941 \mathrm{~cm}^{-1}$ that are, respectively, assigned to the $\mathrm{A}_{1 \mathrm{~g}} \mathrm{Fe}-\mathrm{O}$ phonon mode of $\mathrm{Fe}_{3} \mathrm{O}_{4}$ and a combination of alkenic $\delta(\mathrm{C}-\mathrm{H})$ and a possible magnetic interaction associated with $\mathrm{Fe}_{3} \mathrm{O}_{4} \cdot{ }^{17,31}$ At $6 \mathrm{~h}$, there is an emergence of several other features which have all been described previously. ${ }^{14-19}$ Briefly, they comprise a $\mathrm{C}-\mathrm{C}$ torsion mode of edge carbon atoms contained within a polycyclic aromatic network (506 $\left.\mathrm{cm}^{-1}\right),{ }^{32,33}$ out of plane $\mathrm{C}-\mathrm{H}$ deformations of either an olefinic or aromatic group $\left(807\right.$ and $\left.\left.871 \mathrm{~cm}^{-1}\right)\right)^{31,32}$ alkenic $\delta(\mathrm{C}-\mathrm{H})\left(953 \mathrm{~cm}^{-1}\right),{ }^{14,16}$ and several aromatic $\delta(\mathrm{C}-\mathrm{H})$ modes $\left(1160,1389\right.$, and $\left.1451 \mathrm{~cm}^{-1}\right) \cdot{ }^{14-17}$ Evolution of each of these features is prominent up to $96 \mathrm{~h}$, after which there is effectively little change in the spectral profile.

A significant advantage of using INS is the ability of the technique to determine the concentration of hydrogen within the analyzed samples. ${ }^{34}$ Through previously established calibration procedures, $^{18,24}$ Figure 7 presents the degree of 
(a)
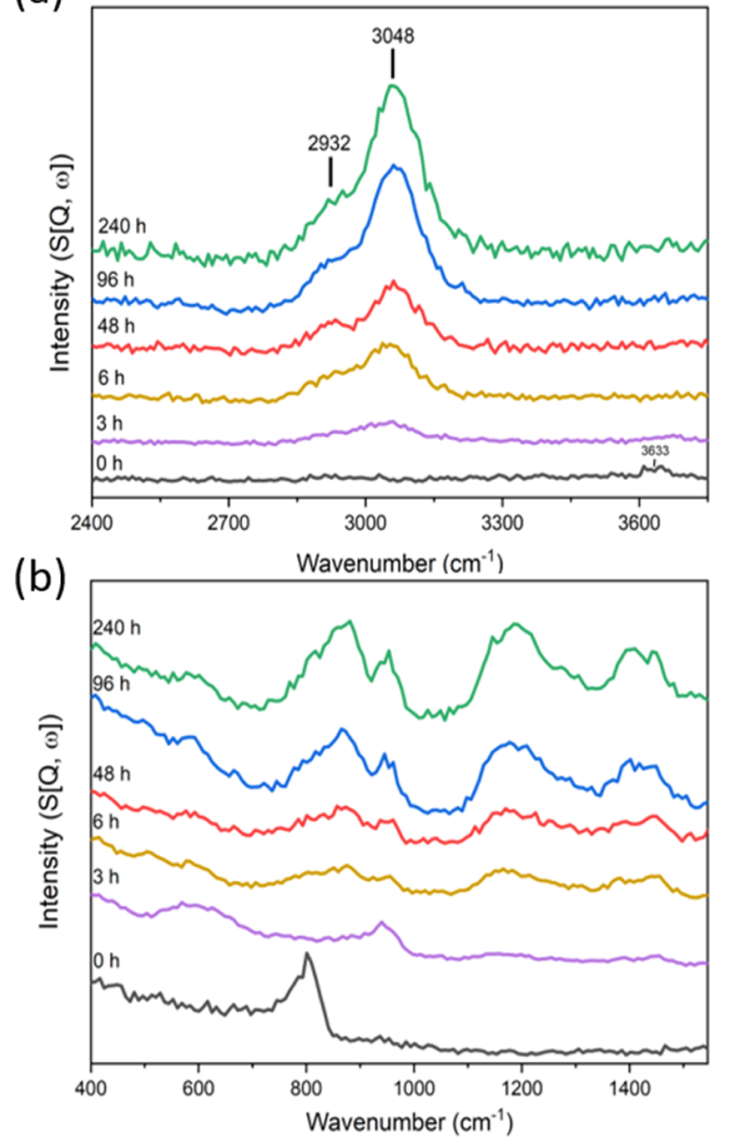

Figure 6. INS spectra for an Fe-based Fischer-Tropsch catalyst after continuous exposure to syngas $\left(\mathrm{CO} / \mathrm{H}_{2}=1: 2\right)$ at $623 \mathrm{~K}$ in the largescale reactor for 0 (black), 3 (purple), 6 (yellow), 48 (red), 96 (blue), and $240 \mathrm{~h}$ (green): (a) incident energy $=650 \mathrm{meV}$ and (b) incident energy $=250 \mathrm{meV}$.

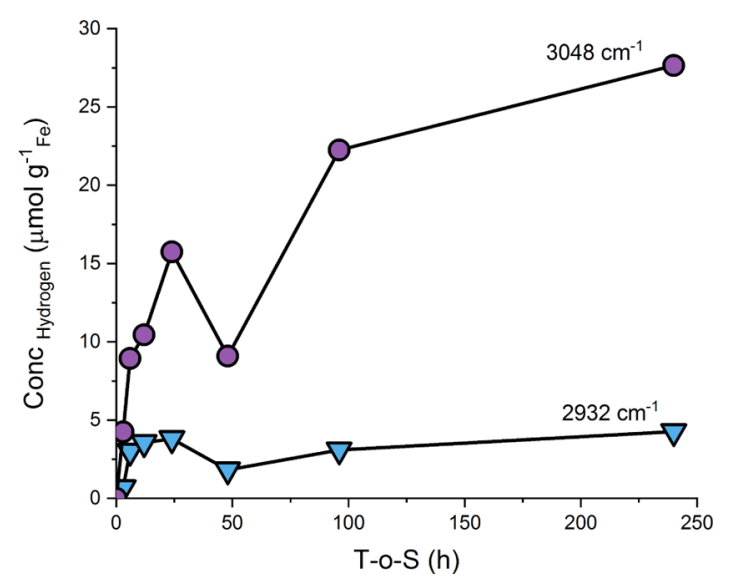

Figure 7. Hydrogen content $\left(\mu \mathrm{mmol} \mathrm{H} \mathrm{g} \mathrm{Fe}^{-1}\right)$ of the $2932 \mathrm{~cm}^{-1}$ (triangles) and $3048 \mathrm{~cm}^{-1}$ (circles) features identified in Figure 6. Data previously reported by Warringham et al. for the period 3-24 h are included in the figure ${ }^{18}$ in order to convey the full evolutionary profile of the hydrocarbonaceous overlayer over a duration of $240 \mathrm{~h}$.

hydrogen retention for the two resolved $\nu(\mathrm{C}-\mathrm{H})$ modes. It is noted that Figure 7 is a combination of two sets of INS data from two separate batches of the same catalyst: $3-24 \mathrm{~h}$ on stream as previously reported by Warringham et al. ${ }^{18}$ and 0 , $48-240 \mathrm{~h}$, as obtained from this investigation. Linking in with comments made in Section 3.2, as no characteristic features were observed in the MS profile at $48 \mathrm{~h}$ (Figure S1), the "dip" in intensity of the INS spectra at $48 \mathrm{~h}$ in Figure 7 is thought to reflect a degree of variance in the testing and post-reaction measurement of different batches of the hematite precatalyst rather than any structural dynamics of the catalyst. Moreover, repeat measurements of calibration standards on MAPS return an error of $\pm 6.2 \%$, ${ }^{24}$ which is consistent with the generally continuous trends observed in these INS spectra of postreaction catalysts. ${ }^{15-18}$ Therefore, it is deduced that the anomalously low value for the $48 \mathrm{~h} \mathrm{sp}^{2}$-hybridized $\nu(\mathrm{C}-\mathrm{H})$ mode in Figure 7 is reflective of some complication in that particular run. It is possible that this could be an unknown problem in the reaction testing procedure but, more likely, it could be due to poor alignment of the sample in the neutron beam. Nonetheless, with the exception of that one data point, Figure 7 essentially conveys a continuous profile.

Figure 7 is characterized by two distinct trends: first, the integrated intensity of the aliphatic $\nu(\mathrm{C}-\mathrm{H})$ stretch at 2932 $\mathrm{cm}^{-1}$ saturates at approximately $24 \mathrm{~h} \mathrm{T-o-S}$; second, the $\mathrm{sp}^{2}$ hybridized $\nu(\mathrm{C}-\mathrm{H})$ stretch at $3048 \mathrm{~cm}^{-1}$, representing olefinic and/or aromatic hydrocarbonaceous moieties, approaches saturation after $100-200 \mathrm{~h} \mathrm{T-o-S}$. This is important and new information, which indicates a degree of previously unrealized complexity in the evolutionary phase of the hydrocarbonaceous overlayer.

\section{DISCUSSION}

In order to better understand the INS profiles, it is first necessary to address the uncertainty connected with the original TPO assignments, as considered toward the end of Section 3.2. Concentrating first on the TPO $\alpha$ peak, this has been assigned to a carbonaceous species that is a precursor for the formation of the hydrocarbonaceous overlayer. ${ }^{18}$ The coincidence of its intensity profile with that of the $\mathrm{sp}^{3}$ hybridized $\nu(\mathrm{C}-\mathrm{H})$ mode (Figure 7 ) more specifically links it to the aliphatic component of the overlayer. However, as exposed in Section 3.2, the TPO $\alpha$ peak could also be linked to iron carbide formation, as XRD (Figure $2 b$ ) shows iron carbide formation to have saturated over the period for which the TPO $\alpha$ peak is generated and consumed. One further possibility for the $\alpha$ feature is that part of its consumption could reflect this species additionally contributing to the growth of the TPO $\beta$ and/or $\gamma$ peaks for extended T-o-S (Figure 5), that is, in accordance with Niemantsverdriet's competition model; ${ }^{18}$ the $\alpha$ feature could simultaneously be a precursor to the TPO $\beta$ and/or $\gamma$ features.

The possible assignment for the TPO $\gamma$ peak is less convoluted than that discussed above for the $\alpha$ peak but, nonetheless, it necessarily requires revision. As noted in Section 3.2, it cannot exclusively be attributed to carbide formation. Given its profile (Figure 5) is broadly coincident that of the $\mathrm{sp}^{2}$-hybridized $\nu(\mathrm{C}-\mathrm{H})$ mode of the hydrocarbonaceous overlayer (Figure 7), an additional contribution of polyaromatic carbon is proposed.

These considerations indicate that the post-reaction TPO plots are more complicated than originally envisaged. ${ }^{18}$ Indeed, it appears that certain peaks can be associated with various chemical transformations. Table 3 presents the revised assignments for the three TPO features connected with ambient pressure $\mathrm{CO}$ hydrogenation over an iron-based FTS catalyst at $623 \mathrm{~K}$. Further analysis is clearly required to 
Table 3. Revised Probable Associations for the Three TPO Features Connected with Ambient Pressure CO Hydrogenation over an Unpromoted Iron-Based FTS Catalyst at $623 \mathrm{~K}$

\begin{tabular}{|c|c|c|}
\hline $\begin{array}{l}\text { TPO } \\
\text { peak }\end{array}$ & $\begin{array}{c}\text { original } \\
\text { assignment }^{18}\end{array}$ & revised assignment \\
\hline$\alpha$ & $\begin{array}{l}\text { reactive } \\
\text { carbon }\end{array}$ & $\begin{array}{l}\text { (i) precursor to aliphatic component of the } \\
\text { hydrocarbonaceous overlayer } \\
\text { (ii) precursor to iron carbide formation } \\
\text { (iii) precursor state to formation of the TPO } \beta \\
\text { and/or } \gamma \text { features }\end{array}$ \\
\hline$\beta$ & $\begin{array}{l}\text { amorphous } \\
\text { carbon }\end{array}$ & amorphous carbon \\
\hline$\gamma$ & iron carbide & $\begin{array}{l}\text { (i) iron carbide } \\
\text { (ii) polyaromatic carbonaceous species }\end{array}$ \\
\hline
\end{tabular}

determine which of the proposed pathways the $\alpha$ component follows. This important matter constitutes "work in progress".

With an improved awareness of the TPO features presented in Figure 5, it is informative to concentrate on connections to the partitioning of hydrogen within the catalyst matrix as a function of T-o-S. Specifically, how does the temporal profile of the hydrocarbonaceous overlayer correspond to that observed for the reaction test data over this extended reaction coordinate? First, the CO hydrogenation test data in Figure 1 indicate the reaction system to be effectively operating in a steady-state regime from ca. $9 \mathrm{~h}$. This is the benchmark time against which other temporal trends may be usefully compared. Interestingly, elemental analysis (Table 1 ) shows $\mathrm{C}$ and $\mathrm{H}$ values to continue to accrue way beyond that period, not achieving saturation values until 100-200 h T-o-S.

The XRD diffractograms (Figure 2) indicate the transition from hematite to Hägg carbide and a contribution from amorphous carbon; this is consistent with the Raman spectra presented in Figure 3. However, while the diffractograms show the extent of amorphous carbon to increase on increasing T-o$\mathrm{S}$, the intensity of the Hägg carbide features has saturated at 48 $\mathrm{h}$. The maintenance of this structure over the period $48-240 \mathrm{~h}$ $\mathrm{T}$-o-S connects with the stable reaction performance observed over this period (Section 3.1); a correlation supportive of the concept that Hägg carbide defines the active phase of a FTS catalyst. $^{8-11}$

The intensity profile for the TPO $\beta$ and $\gamma$ features (Figure 5) broadly matches that observed for the $\mathrm{sp}^{2}$-hybridized carbon $\nu(\mathrm{C}-\mathrm{H})$ mode (Figure 7$)$. This leads to the proposal that, over a period of up to ca. $200 \mathrm{~h} \mathrm{~T}-\mathrm{o}-\mathrm{S}$, the amorphous carbon $(\beta)$ and/or iron carbide and polyaromatic carbonaceous deposits $(\gamma)$ evident in TPO measurements are responsible for the formation of the olefinic and/or aromatic component of the hydrocarbonaceous overlayer. If the $\alpha$ species is in fact a precursor to the $\beta$ or $\gamma$ as suggested above, then the $\alpha$ species is suggested to be the initial stage in a sequential pathway in the development of the hydrocarbonaceous overlayer, that is, $\alpha$ species $\rightarrow \beta$ and/or $\gamma$ species $\rightarrow \mathrm{sp}^{2}$-hybridized $\nu(\mathrm{C}-\mathrm{H})$ mode. This proposal is merely speculative at this stage. Nonetheless, each of the suggested pathways indicate the $\alpha$ species to have an integral role within the development of the evolving catalyst matrix. Indeed, these considerations illustrate the dynamic nature of the evolutionary phase of iron-based FTS catalysts undergoing $\mathrm{CO}$ hydrogenation at elevated temperatures and atmospheric pressure over extended periods of T-o-S.
Returning to the matter of catalytic performance, Table 4 contrasts the reaction times that correspond to completion of a

Table 4. Values of T-o-S That Correspond to Completion of a Particular Component of the Catalyst Evolutionary Process as Determined by (a) Reaction Testing, (b) Elemental Analysis, (c) XRD, (d) TPO, and (e) INS

\begin{tabular}{|c|c|c|}
\hline technique & $\begin{array}{l}\text { component of the } \\
\text { catalyst evolutionary } \\
\text { process }\end{array}$ & $\begin{array}{l}\text { T-o-S corresponding to completion of } \\
\text { a particular component of the catalyst } \\
\text { evolutionary process } / \mathrm{h}\end{array}$ \\
\hline $\begin{array}{r}\text { reaction } \\
\text { testing }\end{array}$ & $\begin{array}{l}\text { steady-state operation } \\
\text { in CO } \\
\text { hydrogenation test } \\
\text { reaction }\end{array}$ & $\sim 9$ \\
\hline \multirow{2}{*}{$\begin{array}{r}\text { elemental } \\
\text { analysis }\end{array}$} & (i) carbon & $100-200$ \\
\hline & (ii) hydrogen & $100-200$ \\
\hline $\begin{array}{l}\text { powder } \\
\text { XRD }\end{array}$ & Hägg carbide & $\leq 48$ \\
\hline \multirow[t]{2}{*}{ ТPO } & (i) $\alpha$ peak & $\sim 50$ \\
\hline & (ii) $\beta$ and $\gamma$ peaks & $100-200$ \\
\hline \multirow[t]{2}{*}{ INS } & $\begin{array}{l}\text { (i) } \nu(\mathrm{C}-\mathrm{H}) \mathrm{sp}^{3}- \\
\text { hybridized carbon }\end{array}$ & $\sim 24$ \\
\hline & $\begin{array}{l}\text { (ii) } \nu(\mathrm{C}-\mathrm{H}) \mathrm{sp}^{2}- \\
\text { hybridized carbon }\end{array}$ & $100-200$ \\
\hline
\end{tabular}

particular component of the catalyst evolutionary process. Most notably, sustained catalytic turnover is attainable over short periods of time ( $\geq 9 \mathrm{~h}$ T-o-S), which can be loosely correlated with the formation of Hägg carbide features $(\leq 48 \mathrm{~h}$ T-o-S). However, against this background, there is a progressive carburization process that leads to distinct profiles for specific entities detectable by TPO and INS. Indeed, modification of the carbonaceous and hydrocarbonaceous entities appears to undergo a relatively slow transitional phase that, seemingly, does not disturb catalyst performance. This slower modification of the catalyst matrix approaches completion over the period 100-200 h T-o-S. Collectively, this work shows that the journey from the hematite precatalyst to a stabilized material capable of supporting sustained syngas turnover is complex and involves a variety of molecular entities, that is, iron oxides, iron carbides, carbonaceous entities, and a hydrocarbonaceous overlayer.

\section{CONCLUSIONS}

Ambient pressure $\mathrm{CO}$ hydrogenation over a promoter-free hematite catalyst at $623 \mathrm{~K}$ has been investigated for extended periods of T-o-S of up to 10 days $(240 \mathrm{~h})$ utilizing approximately $10 \mathrm{~g}$ of catalyst charge. Characterization of the catalyst through INS, elemental analysis, TPO, XRD, and Raman spectroscopy leads to the following conclusions:

- Post-reaction ex situ XRD indicates only the Hägg carbide to be present within the bulk catalyst from $48 \mathrm{~h}$ onward.

- For reaction times $\geq 48 \mathrm{~h}$, TPO measurements show only amorphous carbon (peak $\beta$ ) and iron carbide and polyaromatic carbonaceous species (peak $\gamma$ ) to be present. The reactive carbonaceous species (peak $\alpha$ ) grows and decays to ultimately zero concentration over the period $0-48 \mathrm{~h}$ T-o-S.

- INS analysis of the reacted catalyst samples identifies the presence of $\mathrm{sp}^{2}$ - and $\mathrm{sp}^{3}$-hybridized $\mathrm{C}-\mathrm{H}$ species, with quantification of the $\nu(\mathrm{C}-\mathrm{H})$ modes indicating the concentration of aliphatic $\mathrm{C}-\mathrm{H}$ species to saturate after 
approximately $24 \mathrm{~h} \mathrm{~T}$-o-S. In contrast, the concentration of olefinic/aromatic $\mathrm{C}-\mathrm{H}$ entities progressively increase up to $\sim 200 \mathrm{~h}$ before appearing to reach saturation.

- The development of the amorphous carbon $(\beta)$ and iron carbide + polyaromatic carbonaceous $(\gamma)$ entities that occurs over a catalyst conditioning period of ca. $200 \mathrm{~h}$ correlate with the formation of the olefinic and/or aromatic component of the hydrocarbonaceous overlayer.

- The TPO $\alpha$ species is suggested to play an integral part in the catalyst evolutionary process and may be associated with the following three pathways: (i) a precursor to iron carbide formation; (ii) a precursor to the formation of the aliphatic component of the hydrocarbonaceous overlayer; and (iii) a precursor to either the $\beta$ or $\gamma$ TPO features.

- From inspection of TPO and INS intensity profiles, it is concluded that under the stated reaction conditions, the overall catalyst evolutionary phase requires approximately $200 \mathrm{~h}$ T-o-S to achieve completion.

- Steady-state operation of the catalytic system is not directly coupled to the TPO $\beta$ and $\gamma$ entities, nor is it connected to the development of the olefinic/aromatic component of the hydrocarbonaceous overlayer.

\section{ASSOCIATED CONTENT}

\section{S Supporting Information}

The Supporting Information is available free of charge at https://pubs.acs.org/doi/10.1021/acs.iecr.9b04636.

Full reaction profile for the sample exposed to $\mathrm{CO}$ hydrogenation conditions at $623 \mathrm{~K}$ for $96 \mathrm{~h}$; powder XRD with Rietveld refinement of the calcined hematite catalyst before exposure to reaction conditions; Rietveld refinement of the hematite catalyst after exposure to ambient pressure $\mathrm{CO}$ hydrogenation at $623 \mathrm{~K}$ for 24,96 , and $240 \mathrm{~h}$ T-o-S (PDF)

\section{AUTHOR INFORMATION}

\section{Corresponding Authors}

*Email: pbw@st-andrews.ac.uk (P.B.W.).

*E-mail: David.Lennon@glasgow.ac.uk. Phone: +44-141-3304372 (D.L.).

\section{ORCID $\odot$}

Paul B. Webb: 0000-0003-2532-344X

Stewart F. Parker: 0000-0002-3228-2570

David Lennon: 0000-0001-8397-0528

\section{Notes}

The authors declare no competing financial interest.

\section{ACKNOWLEDGMENTS}

Sasol Ltd., the EPSRC (award reference EP/P505534/1), and the University of Glasgow are thanked for the provision of a postgraduate studentship (ALD). The STFC Rutherford Appleton Laboratory is thanked for access to neutron beam facilities. The Royal Society is thanked for the provision of an Industry Fellowship (PBW). Professor Bob Tooze (Drochaid Research Services, St. Andrews, UK) is thanked for helpful discussions. Dr Giovanni Rossi and Dr James Campbell (School of Chemistry, University of Glasgow) are thanked for assistance with the neutron measurements.

\section{REFERENCES}

(1) De Smit, E.; Weckhuysen, B. M. The Renaissance of Iron-Based Fischer-Tropsch Synthesis: on the Multifaceted Catalyst Deactivation Behaviour. Chem. Soc. Rev. 2008, 37, 2758-2781.

(2) Steynberg, A. P. Introduction to Fischer Tropsch Technology. Studies in Surface Science and Catalysis; Elsevier, 2004;Vol. 152, pp 163.

(3) Van de Loosdrecht, J.; Botes, F. G.; Ciobica, I. M.; Ferreira, A.; Gibson, P.; Moodley, D. J.; Saib, A. M.; Visage, J. L.; Weststrate, C. J.; Niemantsverdriet, J. W. Fischer-Tropsch Synthesis: Catalysts and Chemistry. Comprehensive Inorganic Chemistry II; Eslvier: Oxford, 2013; Vol. 7, pp 525-557.

(4) Ning, W.; Koizumi, N.; Chang, H.; Mochizuki, T.; Itoh, T.; Yamada, M. Phase transformation of unpromoted and promoted $\mathrm{Fe}$ catalysts and the formation of carbonaceous compounds during Fischer-Tropsch synthesis reaction. Appl. Catal., A 2006, 312, 35-44.

(5) de Smit, E.; Cinquini, F.; Beale, A. M.; Safonova, O. V.; van Beek, W.; Sautet, P.; Weckhuysen, B. M. Stability and Reactivity of $\varepsilon$ $\chi-\theta$ Iron Carbide Catalyst Phases in Fischer-Tropsch Synthesis: Controlling $\mu$ c. J. Am. Chem. Soc. 2010, 132, 14928-14941.

(6) Niemantsverdriet, J. W.; Van der Kraan, A. M.; Van Dijk, W. L.; Van der Baan, H. S. Behaviour of Metallic Iron Catalysts during Fischer-Tropsch Synthesis Studied with Mössbauer Spectroscopy, Xray Diffraction, Carbon Content Determination, and Reaction Kinetic Measurements. J. Phys. Chem. 1980, 84, 3363-3370.

(7) Dry, M. E. The Fischer-Tropsch Synthesis, Catalysis: Science and Technology; Springer-Verlag: New York, 1981; pp 160-255.

(8) Gracia, J. M.; Prinsloo, F. F.; Niemantsverdriet, J. W. Mars-van Krevelen-like mechanism of $\mathrm{CO}$ hydrogenation on an iron carbide surface. Catal. Lett. 2009, 133, 257-261.

(9) Shroff, M. D.; Kalakkad, D. S.; Coulter, K. E.; Kohler, S. D.; Harrington, M. S.; Jackson, N. B.; Sault, A. G.; Datye, A. K. Activation of Precipitated Iron Fischer-Tropsch Synthesis Catalysts. J. Catal. 1995, 156, 185-207.

(10) Li, S.; Ding, W.; Meitzner, G. D.; Iglesia, E. Spectroscopic and transient kinetic studies of site requirements in iron-catalyzed FischerTropsch synthesis. J. Phys. Chem. B 2002, 106, 85-91.

(11) Zhang, J.; Abbas, M.; Chen, J. The evolition of Fe phases of a fused iron catalyst during reduction and Fischer-Tropsch synthesis. Catal. Sci. Technol. 2017, 7, 3626-3636.

(12) Pérez-Alonso, F. J.; Herranz, T.; Rojas, S.; Ojeda, M.; Lopez Granados, M.; Terreros, P.; Fierro, J. L. G.; Gracia, M.; Gancedo, J. R. Evolution of the bulk structure and surface species on $\mathrm{Fe}-\mathrm{Ce}$ catalysts during the Fischer-Tropsch synthesis. Green Chem. 2007, 9, 663-670.

(13) Buker, D. M.; Nowicki, L.; Patel, S. A. Activation studies with an iron Fischer-Tropsch catalyst in Fixed bed and stirred tank slurry reactors. Can. J. Chem. Eng. 1996, 74, 399-404.

(14) Hamilton, N. G.; Silverwood, I. P.; Warringham, R.; Kapitán, J.; Hecht, L.; Webb, P. B.; Tooze, R. P.; Parker, S. F.; Lennon, D. Vibrational Analysis of an Industrial Fe-based Fischer-Tropsch Catalyst Employing Inelastic Neutron Scattering. Angew. Chem., Int. Ed. 2013, 52, 5608-5611.

(15) Hamilton, N. G.; Warringham, R.; Silverwood, I. P.; Kapitán, J.; Hecht, L.; Webb, P. B.; Tooze, R. P.; Zhou, W.; Frost, C. D.; Parker, S. F.; Lennon, D. The Application of Inelastic Neutron Scattering to Investigate $\mathrm{CO}$ hydrogenation over an Iron Fischer-Tropsch Synthesis Catalyst. J. Catal. 2014, 312, 221-231.

(16) Warringham, R.; Hamilton, N. G.; Silverwood, I. P.; How, C.; Webb, P. B.; Tooze, R. P.; Zhou, W.; Frost, C. D.; Parker, S. F.; Lennon, D. The Application of Inelastic Neutron Scattering to Investigate a Hydrogen Pre-treatment Stage of an Iron FischerTropsch Catalyst. Appl. Catal., A 2015, 489, 209-217.

(17) Warringham, R.; McFarlane, A. R.; MacLaren, D. A.; Webb, P. B.; Tooze, R. P.; Taylor, J.; Ewings, R. A.; Parker, S. F.; Lennon, D. The Application of Inelastic Neutron Scattering to Explore the Significance of a Magnetic Transition in an Iron-Based FischerTropsch Catalyst that is Active for the Hydrogenation of CO. J. Chem. Phys. 2015, 143, 174703. 
(18) Warringham, R.; Davidson, A. L.; Webb, P. B.; Tooze, R. P.; Ewings, R. A.; Parker, S. F.; Lennon, D. Examining the temporal behaviour of the hydrocarbonaceous overlayer on an iron based Fischer-Tropsch catalyst. RSC Adv. 2019, 9, 2608-2617.

(19) Warringham, R.; Davidson, A. L.; Webb, P. B.; Tooze, R. P.; Parker, S. F.; Lennon, D. Perspectives on the effect of sulfur on the hydrocabronacous overlayer on iron Fischer-Tropsch catalysts. Catal. Today 2020, 339, 32-39.

(20) Borodziński, A.; Cybulski, A. The kinetic model of hydrogenation of acetylene-ethylene mixtures over palladium surface covered by carbonaceous deposits. Appl. Catal., A 2000, 198, 51-66.

(21) Warringham, R.; Bellaire, D.; Parker, S. F.; Taylor, J.; Ewings, R. A.; Goodway, C. M.; Kibble, M.; Wakefield, S. R.; Jura, M.; Dudman, M. P.; Tooze, R. P.; Webb, P. B.; Lennon, D. Sample environment issues relevant to the acquisition of inelastic neutron scattering measurements of heterogeneous catalyst samples. J. Phys.: Conf. Ser. 2014, 554, 012005.

(22) Mitchell, P. C. H.; Parker, S. F.; Ramirez-Cuesta, A. J.; Tomkinson, J. Vibrational Spectroscopy Using Neutrons with Application in Chemistry, Biology, Material Science and Catalysis. Series on Neutron Techniques and Applications; World Scientific: Singapore, 2005; Vol. 3.

(23) Parker, S. F.; Lennon, D.; Albers, P. W. Vibrational Spectroscopy with Neutrons: A Review of New Directions. Appl. Spectrosc. 2011, 65, 1325-1341.

(24) Silverwood, I. P.; Hamilton, N. G.; Laycock, C. J.; Staniforth, J. Z.; Ormerod, R. M.; Frost, C. D.; Parker, S. F.; Lennon, D. Quantification of Surface Species Present on a Nickel/Alumina Methane Reforming Catalyst. Phys. Chem. Chem. Phys. 2010, 12, 3102-3107.

(25) Shroff, M. D.; Datye, A. K. The importance of passivation in the study of iron Fischer-Tropsch catalysts. Catal. Lett. 1996, 37, 101106.

(26) Silverwood, I. P.; Hamilton, N. G.; McFarlane, A. R.; Kapitán, J.; Hecht, L.; Norris, E. L.; Mark Ormerod, R.; Frost, C. D.; Parker, S. F.; Lennon, D. Application of Inelastic Neutron Scattering to Studies of $\mathrm{CO} 2$ Reforming of Methane Over Alumina-Supported Nickel and Gold-Doped Nickel Catalysts. Phys. Chem. Chem. Phys. 2012, 14, 15214-15225.

(27) Galvis, H. M. T.; Koeken, A. C. J.; Bitter, J. H.; Davidian, T.; Ruitenbeek, M.; Dugulan, A. I.; de Jong, K. P. Effect of sodium and sulfur on catalytic performance of supported iron catalysts for the Fischer-Tropsch synthesis of lower olefins. J. Catal. 2013, 303, 22-30.

(28) Tuinstra, F.; Koenig, J. L. Raman spectrum of graphite. J. Chem. Phys. 1970, 53, 1126-1130.

(29) Pimenta, M. A.; Dresselhaus, G.; Dresselhaus, M. S.; Cançado, L. G.; Jorio, A.; Saito, R. Studying disorder in graphite-based systems by Raman spectroscopy. Phys. Chem. Chem. Phys. 2007, 9, 12761290.

(30) Sadezky, A.; Muckenhuber, H.; Grothe, H.; Niessner, R.; Pöschl, U. Raman microspectroscopy of soot and related carbonaceous materials: Spectral analysis and structural information. Carbon 2005, 43, 1731-1742.

(31) Chamritski, I.; Burns, G. Infrared- and Raman-Active Phonons of Magnetite, Maghemite, and Hematite: A Computer Simulation and Spectroscopic Study. J. Phys. Chem. B 2005, 109, 4965-4968.

(32) Lin-Vein, D.; Colthup, N. B.; Fateley, W. G.; Graselli, J. G. The Handbook of Infrared and Raman Characteristic Frequencies of Organic Molecules; Academic Press: Boston, 1991.

(33) Albers, P. W.; Pietsch, J.; Krauter, J.; Parker, S. F. Investigations of Activated Carbon Catalyst Supports from Different Natural Sources. Phys. Chem. Chem. Phys. 2003, 5, 1941-1949.

(34) Albers, P. W.; Lennon, D.; Parker, S. F., Catalysis. Neutron Scattering: Applications in Biology, Chemistry, and Materials Science; Elsevier, 2017; Vol. 49, pp 279-348. 